\title{
A construção identidades dos alunos de EaD através dos seus discursos em um fórum de discussão 1
}

\author{
Ruhena Kelber Abrão ${ }^{2}$ \\ Juliana de Souza da Silva ${ }^{3}$ \\ João Alberto da Silva ${ }^{4}$
}

\section{Resumo}

Este estudo tem como objetivo investigar os discursos dos alunos da modalidade de Educação à Distância $(\mathrm{EaD})$ produzidos em fóruns de discussão no Ambiente Virtual de Aprendizagem (AVA). Tenciona-se conhecer a identidade dos estudantes de EaD, conhecer de forma mais aprofundada quem são estes sujeitos, através de um exame detalhado de suas falas. No espaço da Educação a Distância, a relação entre alunos dáse, diferentemente do ensino convencional, através da mediação dos recursos tecnológicos. Entende-se que é possível construir perfis de alunos da $\mathrm{EaD}$ a partir dos textos apresentados nos fóruns. No ambiente virtual, pressupõe-se que os estudantes corporificam-se por meio do seu discurso. Por não existir a possibilidade de haver uma presença física, a configuração do sujeito se dá através da sua própria fala.

Palavras Chave: Educação a Distância. Discurso. Identidade.

The construction of identities of students from Distance Education through their discourses in forums

Abstract: This study intends to research discourses of students from the model of Distance Education. Those discourses were produced in message board forums in The Learning Virtual Settings. Our objective is to know the students identities, to know in a deeper way who are those subjects, by doing a detailed examination of their speeches. In Distance Education, the relationship between students happens, different from the traditional education, with mediation of the technological resources. We believe that it is possible to construct students' profiles through the texts exposed in the forums. In the Virtual Setting, it is supposed students body themselves through their discourse.

\footnotetext{
${ }^{1}$ Este estudo contou com o financiamento da Fundação de Amparo à Pesquisa do Rio Grande do Sul FAPERGS e Coordenação de Aperfeiçoamento de Pessoal de Nível Superior - CAPES, a quem agradecemos, vivamente, o apoio.

${ }^{2}$ Mestre em Educação Física. Professor Pesquisar da Universidade Federal de Pelotas UFPEL. Bolsista FAPERGS. Núcleo de Estudos em Epistemologia e Educação em Ciências - NUEPEC. kelberabrao@gmail.com

${ }^{3}$ Licencianda em Letras da Universidade Federal do Rio Grande - FURG. Bolsista CNPq. Núcleo de Estudos em Epistemologia e Educação em Ciências - NUEPEC. julianaholmes@ hotmail.com

${ }^{4}$ Doutor em Educação. Professor da Universidade Federal do Rio Grande - FURG. Núcleo de Estudos em Epistemologia e Educação em Ciências - NUEPEC. joaosilva@ furg.br
} 
Because there is not any way of be present physically, the student configuration occurs in her/his speech.

Keywords: Distance Education. Dircourse. Identity.

\section{Primeiras Palavras: Os Ambientes Virtuais de Aprendizagem}

A emergência das Tecnologias da Informação e da Comunicação vem modificando pungentemente a concepção contemporânea de educação. Essa mudança traz consigo a necessidade de reformulação de vários conceitos caros a quem se dedica a pesquisar sobre educação e sociedade, por ora: aula, tempo, espaço, pesquisa, documento e professor.

Hoje, ainda entendemos por aula um espaço e um tempo determinados. Mas, esse tempo e esse espaço, cada vez mais, serão flexíveis. O professor continuará "dando aula", e enriquecerá esse processo com as possibilidades que as tecnologias interativas proporcionam: para receber e responder mensagens dos alunos, criar listas de discussão e alimentar continuamente os debates e pesquisas com textos, páginas da Internet, até mesmo fora do horário específico da aula. Há uma possibilidade cada vez mais acentuada de estarmos todos presentes em muitos tempos e espaços diferentes. Assim, tanto professores quanto alunos estarão motivados, entendendo "aula" como pesquisa e intercâmbio. Nesse processo, o papel do professor vem sendo redimensionado e cada vez mais ele se torna um supervisor, um animador, um incentivador dos alunos na instigante aventura do conhecimento (Moran, 2011).

No tempo presente, não se planeja mais uma aula sob os mesmos pressupostos, isto é, quadro-negro e giz não são mais coadjuvantes da cena juntamente com o protagonismo operado pelo professor em frente a uma classe repleta de alunosespectadores. Tanto o modelo de educação presencial quanto, obviamente, o modelo a distância estão inundados de referências virtuais.

Nota-se que educação não pode ser mais pensada desligada da tecnologia, podendo ser levado em conta o seu uso enquanto ferramenta pedagógica (na educação presencial contemporânea), enquanto meio sui generis de existência da própria educação $(\mathrm{EaD})$ e enquanto elemento constituidor da identidade cultural contemporânea que, por tanto tempo, estabilizou o mundo social, estão em declínio, fazendo surgir novas identidades e fragmentando o indivíduo.

\footnotetext{
As novas tecnologias da inteligência individual e coletiva estão modificando profundamente os dados do problema da educação e da formação. O que deve ser aprendido não pode mais ser planejado, nem precisamente definido de maneira antecipada. Os percursos e os perfis de competência são, todos eles, singulares e está cada vez menos possível canalizar-se em programas ou currículos que sejam válidos para todo o mundo. Devemos construir novos modelos do espaço dos conhecimentos (Lévy, 1999).
}

No AVA, o discurso dos sujeitos configura-se significante, uma vez que a interação entre alunos e professores ocorre unicamente por meio da linguagem escrita. Nesse sentido, são as palavras os meios pelos quais os sujeitos envolvidos no processo de aprendizagem constroem suas próprias identidades. A interação entre alunos, 
orientadores e tutores na Educação a Distância dá-se através de ciberespaços que compreendem o Ambiente Virtual de Aprendizagem. Desta forma, os AVA são espaços disponíveis on-line para o aprendizado. Partindo do estudo sobre aprendizado on-line de Manson (1998), podemos classificar os ambientes virtuais em três tipos:

Ambiente instrucionista: centrado no conteúdo (que pode ser impresso) e no suporte que são tutorias ou formulários enviados por e-mail. Normalmente são respondidos por outras pessoas (monitores) e não exatamente pelo autor. A interação é mínima e a participação on-line do estudante é praticamente individual. Este tipo de ambiente é o mais comum e representa o tradicional curso instrucionista, no qual a informação é transmitida como aula expositiva presencial

Ambiente interativo: centrado na interação on-line, na qual a participação é essencial no curso. O objetivo é atender também as expectativas dos participantes e ocorre muita discussão e reflexão. Os materiais têm o objetivo de envolver e é desenvolvido no decorrer do curso com as opiniões e reflexões dos participantes e com as ideias formuladas nas áreas de discussão. Existe o incentivo à liberdade e responsabilidade de cada um escolher o material desejado e fazer suas próprias interpretações. As atividades podem ser organizadas em temas de interesses e profissionais externos podem ser convidados para conferencias. Neste caso, o papel do professor é mais intenso, pois as atividades são criadas no decorres do mesmo. Nesse tipo de ambiente ocorrem atividades síncronas, como chats, por exemplo.

Ambiente cooperativo: seu objetivo é o trabalho colaborativo e participação online. Existe muita interação entre os participantes através da comunicação on-line, construção de pesquisas, descobertas, de novos desafios e soluções. O conteúdo do curso é fluido e dinâmico e determinado pelos indivíduos do grupo. O suporte e orientação existem, mas neste caso é menor. É um curso também diferente do presencial por possibilitara construção de comunidades de aprendizes. É importante que todos tenham um bom relacionamento e proximidade.

Nos ambientes colaborativos e cooperativos, os participantes devem estar envolvidos com seu próprio aprendizado, surgindo assim um conceito chave na $\mathrm{EaD}$ : Autonomia. Segundo Kenski (2007), autonomia seria uma atribuição de responsabilidade muito mais forte para o aluno, o que requer mais autodidaxia. A partir disso, cada aluno segue o seu próprio ritmo de trabalho, estudo e pesquisa.

É preciso que os alunos ganhem autonomia em relação às suas aprendizagens, que consigam administrar os seus tempos de estudo, que saibam selecionar os conteúdos que mais lhe interessam, que participem das atividades, independentes do horário ou local em que estejam(...) é preciso que se organizem novas experiências educacionais em que as tecnologias possam ser usadas em processos cooperativos de aprendizagem, em que se valoriza o dialogo e a participação permanente de todos os envolvidos no processo (2007, p.73)

O foco deve ser articular o aprendizado do sujeito com o seu contexto e seu conhecimento de mundo, procurando sempre incentivar o senso de colaboração. No caso em estudo o ambiente utilizado para este trabalho foi o Modular Object-Oriented 
Dynamic Learning Environment - MOODLE, um software livre de apoio a aprendizagem. Este pode ser classificado como interativo, a medida que são disponibilizados materiais on-line para estudo, existem áreas de discussão, as quais visa, à troca de informações e reflexões, e há uma orientação constante por parte de professores e tutores.

\section{Tecnologia da Informação e Comunicação na Educação}

A forma de ensino on-line é uma das expansões mais rápidas no Ensino Superior. A partir de 1998 cresceu o envolvimento de Instituições de Ensino Superior com cursos de educação a distância. Esse envolvimento foi, em grande parte, para cursos de graduação em formação de professores, principalmente, Pedagogia e especializações para professores atuantes na Educação Básica, em efetivo exercício. Nesse sentido, a Universidade Federal do Rio Grande oferece um curso de pós graduação lato sensu de Tecnologia da Informação e Comunicação na Educação (TICEDU) é ofertado.

A proposta central do TIC-EDU é proporcionar a formação continuada de professores atuantes na educação básica pra que estes promovam o ensino a partir das metodologias educativas com base construtivista valendo-se das tecnologias da comunicação e informação. Através do trabalho envolvendo a interdisciplinareidade, os projetos de aprendizagem se configuram como trabalhos coletivos de investigação realizados pelos alunos, a partir de suas questões e vivências, partindo do levantamento de suas certezas provisórias e de suas dúvidas temporárias para atingir a comunicação do conhecimento construído (FAGUNDES, 2006).

Utilizando as diferentes linguagens, oral, textual, hipertextual entre outras, o curso propõe um trabalho que visa romper as barreiras da disciplinaridade existentes na escola. Desta forma, construir uma comunidade virtual comprometida com a sua própria aprendizagem de forma coletiva e cooperativa, buscando proporcionar vivências de telepresença com possibilidade de convivência dos sujeitos com diferentes realidades.

Na referida especialização, a primeira atividade proposta aos educandos é:

Este é nosso primeiro fórum de discussão, e esse espaço foi criado para que juntos possamos conhecer ideias e concepções de cada um, relacioná-las aos textos disponibilizados nesta aula, problematizá-las e reconstruí-las através da convivência. Queremos que participem considerando essas questões e interagindo com os colegas para que realmente possamos construir uma discussão coletiva. Que dificuldades e potencialidades você percebe na aprendizagem através da EaD?

O fórum, enquanto ferramenta pedagógica utilizada na modalidade de educação à distância, mostra-se como um desafio a ser construído continuamente. Uma vez que, ele se configura como um simulacro virtual do espaço da sala de aula, logo certas situações ocorridas no ambiente escolar tradicional parecem ser reproduzidas na utilização de novas tecnologias na educação. Ao passo que, surgem novas possibilidades de atuação educativa e de pesquisa, ora potencializadas pela dinâmica de comunicação oportunizadas pela web e pela própria ferramenta. 
No fórum especifico deste estudo, foram observados os discursos produzidos por 20 alunos acerca de um tema proposto pelos professor-tutor*. Todos deveriam discutir sobre as dificuldades e potencialidades da modalidade de EaD. Para participar do fórum de discussão os estudantes tiveram de ler e refletir criticamente sobre o texto "Ser aluno na modalidade de Ensino a Distância" (Moura, 2010) e ver a apresentação "Diálogo e autonomia".

Os discursos foram analisados segundo a perspectiva da Análise Textual Discursiva (ATD) seguindo as orientações apresentadas por Moraes e Galliazzi (2007). Nessa perspectiva, propõe-se uma análise através da qual o material linguístico (as falas dos estudantes) passa por um processo de desconstrução e reconstrução gerando a emergência de novos entendimentos acerca do que é estudado. Primeiro, busca-se examinar os enunciados mais significativos a fim de chegar às unidades constituintes. Feita a fragmentação das falas, o foco é o estabelecimento de relações, pelo qual se possibilita combinar as unidades e estabelecer categorias, a fim de captar o novo emergente. Por fim, após penetrar intensamente nos processos discursivos, produz-se o metatexto no qual é apresentado a compreensão renovada do fenômeno estudado.

Importa observar que a leitura e a significação/interpretação dos discursos dos estudantes da EaD apresenta alguns dos possíveis sentidos que podem ser dados a estes materiais linguísticos. Admite-se que todo o processo de leitura e interpretação de um texto envolve as intenções do autor, os pressupostos teóricos do leitor e o contexto semântico em que se apresenta. Por essa razão, entende-se que um único significante pode possibilitar a construção de uma multiplicidade de sentidos. Portanto, as significações explicitadas neste estudo são assumidas como uma possibilidade.

\section{Resultados}

A construção das identidades dos alunos é atravessada pelas experiências destes e pelo discurso da própria EaD. Quando os estudantes se encontram nessa modalidade de ensino há um estranhamento inicial, uma vez que o espaço de interação, o tempo e a metodologia são novos. O sujeito depara-se com um desafio, acostumar-se com o novo processo de aprendizagem através da $\mathrm{EaD}$.

\subsection{A posição do aluno diante das dificuldades e potencialidades}

Reitera-se que, no Fórum, os alunos deveriam refletir sobre as suas concepções acerca da $\mathrm{EaD}$ e as questões abordadas nos materiais lidos e, ainda, expor as dificuldades e potencialidades que observam no processo de aprendizagem na EaD.

Notou-se que as dificuldades expostas pelos estudantes de EaD apresentam um caráter de transitoriedade. Os problemas são entendidos como barreiras iniciais que 
podem ser progressivamente atenuadas quando os alunos dão-se conta de que outros colegas já enfrentaram problemas similares e conseguiram ultrapassá-los.

S3: Foi muito importante a leitura que fiz da sua reflexão, pois é o meu primeiro curso à distância e sua colocação, quando afirma que a distância dos colegas e professores é mais virtual do que real, de certa forma, me tranquilizou, ao perceber que parte das minhas dificuldades já foram sentidas e superadas por outros colegas.

S2: (...) acrescento que se não houver comprometimento de todas as partes vamos observar diversas dificuldades.

Outro aspecto importante é o fato de que os estudantes tendem a se adaptar as dificuldades que enfrentam no momento em que tomam consciência do "novo". Este "novo" não se refere apenas a metodologia de ensino, que se distingui drasticamente do tradicional ensino presencial, ou a interação através do AVA, mas também relaciona-se as novas necessidades dos alunos. Em geral, para ser discente na $\mathrm{EaD}$ o individuo precisa assumir uma nova postura frente ao processo de ensino e aprendizagem, e concomitantemente isso causa uma sensação de estranhamento:

S3: Para mim, que inicio esta modalidade de ensino, as dificuldades, neste momento, parecem ser muitas. É diferente este começo, é estranho o fato de não estar em contato "físico" com os outros professores e colegas.

Deve-se destacar que alguns alunos utiliza a expressão "resistência ao novo" fazendo referência aos preconceitos e mitos relacionados aos cursos da $\mathrm{EaD}$. Conforme estes estudantes, em geral, as pessoas acreditam que essa modalidade de ensino contribui para o ato de plágio e que os cursos oferecidos têm qualidade inferior aos presenciais. Dessa forma, percebe-se que a dificuldade enfrentada por estes sujeitos não se relaciona diretamente com o processo de aprendizagem através da $\mathrm{EaD}$, mas está ligada a uma falsa ideia difundida em alguns meios sociais.

Percebeu-se uma discrepância nos discursos dos alunos iniciantes em EaD e os que já fizeram algum curso desta modalidade. Os iniciantes têm dificuldades de adaptação à nova metodologia de ensino, na qual não há contato físico e é preciso ser autônomo e disciplinado, em relação a organização do tempo. Por outro lado, os nãoiniciantes posicionam-se de forma antagônica, eles acreditam ter superados as dificuldades que enfrentaram na $\mathrm{EaD}$, como é possível observar no seguinte trecho:

S1: Com certeza posso afirmar que a maior dificuldade que eu via na EaD era a distância física entre alunos e professores, mas como já realizei outros cursos nessa modalidade, vi que isto não é problema, visto a variedade de meios dentro do AVA ou fora (MSN, skype, orkut), o que torna essa distância mais "virtual" do que real.

\subsection{A importância do "eu”" no processo de aprendizagem na EaD}

De modo geral, a maioria dos alunos da $\mathrm{EaD}$ acredita que a superação das dificuldades iniciais e o alcance das potencialidades nessa modalidade de ensino dependem, efetivamente, do sujeito. Linguisticamente, notou-se nas falas dos estudantes 
a recorrência dos pronomes possessivos "meu" e "minha" minhas dificuldades, minha autonomia, minha aprendizagem, meu tempo; da flexão dos verbos na primeira pessoa do singular ou primeira pessoa do plural nossas responsabilidades, nosso comprometimento e da expressão "dificuldades do(s) aluno(s)" e "potencialidades do(s) aluno(s)". Esses elementos confirmam a posição central do sujeito dentro da EaD. No discurso do sujeito 12, é possível observar a questão do "eu":

\begin{abstract}
S12: Após um questionamento, surgiu a questão das dificuldades encontradas. Quando optamos por realizar uma aprendizagem, seja de que nível for à distância, devemos ter bem focados que o principal ator desta aprendizagem será o "eu", pois não teremos o contato físico frequente a que estamos acostumados, não teremos o horário pré estabelecido pela instituição ou similar para a troca de experiências, não teremos o contato "real" como os amigos para também comentar esta troca de experiências, ao meu ver o problema em potencial da dificuldade encontrada em uma $\mathrm{EaD}$, é a organização da autonomia, visto que não estamos acostumados a este tipo de condição, onde "eu" delimito meu horário, meu espaço, minhas condições..., para efetivação desta aprendizagem.
\end{abstract}

Além da ideia do "eu", emerge no discurso deste sujeito um elemento que chama atenção. O fato de ser o "eu" o sujeito responsável pela aprendizagem configura uma dificuldade. Nesse sentido, pode-se questionar o porquê dessa proposição, uma vez que em outras modalidades de educação o aluno também exerce um papel central no processo de aprendizagem, em outras palavras, ele é o ator da produção de saberes. Supõe-se que seja reflexo da concepção de que o principal ator da aprendizagem na escola, onde se tem o ensino presencial, é o professor. Nessa perspectiva, entende-se que o aluno é coadjuvante no sistema tradicional, pelos menos em relação à delimitação do horário, do espaço e das outras condições necessárias para a efetivação da aprendizagem.

Por outro lado, essa ênfase sobre o "eu" (o sujeito) apresentada pelos estudantes, também pode ser interpretada como a incorporação de um discurso recorrente no campo da EaD. Em geral, entende-se que o estudante precisa ter autonomia sobre a sua aprendizagem, tornando-se assim, o construtor dos seus próprios saberes. Através da leitura dos textos indicados pelos professores os alunos reproduzem um discurso difundido no campo de estudos da EaD.

A reprodução do discurso incorporado, no decorrer do desenvolvimento das discussões no Fórum, parece influir de maneira decisiva para o posicionamento dos estudantes diante da aprendizagem através da $\mathrm{EaD}$. De modo geral, eles não apenas "repetem" o discurso, mas tem-no incorporado de tal forma, que assumem a identidade do "estudante" que é responsável, comprometido, organizado, disciplinado, etc. A ideia de que o aluno possui autonomia, neste novo método de ensino, por exemplo, primeiramente, é reportada na fala dos estudantes como uma "repetição" do que os teóricos dizem sobre a modalidade da $\mathrm{EaD}$. Em um segundo momento, observa-se uma assimilação desta ideia através de uma tomada de consciência de que realmente há uma posição autônoma dos estudantes.

Vale ressaltar que este mesmo discurso é atravessado pelas vivências empíricas dos indivíduos, por isso, não se pode dizer que há um discurso único e homogêneo. Por essa razão, percebeu-se que, no que diz respeito aos desafios enfrentados, por exemplo, os estudantes apresentam diferentes opiniões na classificação da maior dificuldade.

S1: (...) Com certeza posso afirmar que a maior dificuldade que eu via na EaD era a distância física entre os alunos e professores... 
S8: (...) Já a dificuldade maior que percebo na EDA, é a resistência ao novo, algumas pessoas alegam que a EAD é de baixa qualidade, que estimula o plágio, que os cursos são mais fáceis que os presenciais, mas acredito que isso é apenas falta de informação das mesmas...

S10: Não sou novata em relação ao ensino à distância e sei bem que surgem muitas dificuldades, principalmente a nossa capacidade de conseguir aliar nosso cotidiano com a família e trabalho com o ensino a distância...

S12: (...) ao meu ver o problema em potencial da dificuldade encontrada em uma EaD, é a organização da autonomia, visto que não estamos acostumados a este tipo de condição, onde "eu" delimito meu horário, meu espaço, minhas condições..., para a efetivação da aprendizagem.

Há uma discrepância no que diz respeito da ideia de pertencimento. Tem-se aqueles que se posicionam como sujeitos pertencentes a modalidade de $\mathrm{EaD}$ e que mostram um olhar "de dentro" paras explicitar as suas dificuldades e as suas potencialidades. Diferentemente, outros parecem se afastar e mostrar um "olhar de fora", uma vez que constroem sua fala escrevendo "o estudante de EaD precisa". Esses dois aspectos podem ser observados nos fragmentos abaixo:

S3: (...) quando afirma que a distância dos colegas e professores é mais virtual do que real, de certa forma, me tranqüilizou, ao perceber que parte das minhas dificuldades já foram sentidas e superadas por outros colegas.

S4: Para ser estudante em Educação à Distância é preciso criar um ambiente que favoreça a minha aprendizagem, onde o essencial é construir a minha autonomia, organizar o meu tempo e dar prioridade aos estudos.

S5: O estudante na EaD, deve ser coerente e responsável pelo seu processo de ensino, é o aluno que busca a sua interação com o ambiente virtual, colegas, tutores e professores.

S6: (...) O aluno EaD é responsável pela busca do próprio conhecimento, portanto não é um aluno passivo que depende somente do professor e de seus respectivos conteúdos, ao contrário, e um aluno que por necessidade e escolha deve ser autônomo e ativo.

S13: (...) Inicialmente destaco que é imprescindível que o estudante deseje realmente a formação que busca, porque é necessário ter determinação, disciplina e organização para que se torne responsável pela sua aprendizagem.

\subsection{Ser um estudante na EaD}

Importa reiterar que o objetivo dos alunos no fórum de discussão era apresentar de forma crítica quais são as dificuldades e as potencialidades da $\mathrm{EaD}$. Mais que dificuldades e potencialidades, percebeu-se que nas falas dos sujeitos subjaziam as necessidades para ser um aluno dessa modalidade. Ter autonomia, comprometimento, responsabilidade, disciplina, organização e persistência funcionam como os princípios utilizados para suprir as dificuldades iniciais e alcançar as potencialidades.

$\mathrm{Na}$ fala dos estudantes, chamou-se atenção o uso dos verbos e formas verbais "requer", "é preciso", "deve ser", "é necessária(o)", "precisa" em: requer disponibilidade, comprometimento e persistência para tornar-se um bom aluno; para ser estudante em Educação à distância é preciso/ é preciso criar; o estudante 
na EaD deve ser; é necessário ter determinação, disciplina e organização; o educando precisa buscar/um estudante em EaD precisa ser. Parece haver uma consciência dos estudantes sobre as exigências desta nova modalidade de ensino, eles impõe-se um "dever ser", uma vez que são chamados a assumir as responsabilidades da construção de seus saberes.

Logo, a autonomia parece configurar a palavra-chave quando se pretende definir o caráter do estudante na EaD:

S6: O aluno EaD é responsável pela busca do próprio conhecimento, portanto não é um aluno passivo que depende somente do professor e de seus respectivos conteúdos, ao contrário, é um aluno que por necessidade e escolha deve ser autônomo e ativo. Muitas escolas e universidades tem como princípio e ou objetivo formar alunos autônomos, mas sabemos que para isso acontecer há necessidade de grandes reformas pedagógicas e um bom exemplo de ensino-aprendizagem autônomo para as outras modalidades de ensino é o trabalho desenvolvido no Ensino à Distância.

S13: (...) é necessário eleger os temas na qual julgue ter mais dificuldades e/ou que considere mais importantes para fazer uma abordagem mais ampla acerca dos mesmos tendo a iniciativa de pesquisar em diferentes fontes, materiais inerentes a esses temas. Adquirindo assim o bom hábito de aprofundar os conhecimentos de forma autônoma caracterizando-se como sujeito ativo no processo de ensino aprendizagem.

S14: O ensino a distância implica, sobretudo, por parte do aluno que tem de movimentar-se para construir seu conhecimento, usufruir das condições oferecidas e não esperar que lhe sejam ensinadas em uma aula. Criam-se condições para que o aluno perceba que com os materiais adequados e boas orientações pode e deve construir a própria aprendizagem de maneira autônoma, com dedicação e envolvimento.

Faz-se necessária uma ressalva quanto ao modo como os alunos encaram a aprendizagem através da EaD. Embora eles reconheçam o papel central do sujeito no processo de aprender, também entendem que o trabalho em equipe é essencial. Por isso, nota-se que os estudantes percebem a troca de opiniões e de reflexões, no ambiente Fórum de discussão, como uma atividade de interação que corrobora para a sua própria auto-aprendizagem.

\section{Considerações Finais}

Através da análise das falas dos estudante e da consequente impregnação nos processos discursivos, pode-se construir os perfis dos alunos em relação ao modo como se posicionam discursivamente frente as dificuldades e potencialidades da EaD. Vale destacar que, em geral, cada fala apresentou características singulares e, por isso, tornase inviável generalizar qualquer um dos resultados explicitados neste trabalho. É preciso lembrar que este estudo se deu por meio de um exame detalhado dos discursos de sujeitos sócio-historicamente contextualizados.

No que diz respeito às dificuldades destacam-se:

PERFIL 1: neste encontram-se os sujeitos que acreditam que as dificuldades são iniciais e que podem ser superadas se houver persistência, comprometimento e disciplina do aluno no processo de aprendizagem da EaD. Nesse sentido, pode-se dizer que eles 
entendem que as dificuldade são "do aluno" e na "da EaD", em outra palavras, o sujeito exerce o papel principal na superação dos problemas iniciais. Além disso, há uma perspectiva positiva, uma vez que a superação dos desafios.

PERFIL 2: alguns alunos deparam-se com problemas difíceis de superar para quem é iniciante. A falta de contato físico, o desconhecimento da utilização das ferramentas tecnológicas, a falta de acesso a internet de boa qualidade, a sensação de solidão, etc. constituem dificuldades a serem ultrapassadas. No entanto, ainda que os estudantes estejam conscientes dessa possibilidade de superação através persistência, comprometimento e disciplina, na prática ainda não a efetivaram.

Quanto às potencialidades:

PERFIL 1: neste encontram-se os estudantes que percebem a EaD como uma modalidade de ensino que apresenta muitas potencialidades, no entanto para alcançá-las depende da postura do aluno diante do processo de aprendizagem. É possível desenvolver autonomia, comprometimento e organização através desta modalidade de ensino. $\mathrm{O}$ aluno assume um papel ativo diante da sua aprendizagem, precisa organizar seus horários de estudo, tem a oportunidade de fazer sua própria auto-avaliação...

PERFIL 2: alguns alunos entendem que a superação das dificuldades está diretamente ligada as potencialidades. Assim, as potencialidades são construídas pelos sujeitos conforme eles ultrapassam os problemas iniciais.

Logo, pode-se observar que estes perfis correspondem às identidades construídas pelos alunos através da Educação a Distância. De modo geral, é possível afirmar que todos estão relacionados aos posicionamentos assumidos pelos sujeitos, enquanto estudantes da EaD. Posicionamentos, estes, que emergem nos discursos que configuram a corporificação dos sujeitos no ambiente virtual.

\section{Referências}

FAGUNDES, Lea. Aprendizes do Futuro: as inovações começaram!. Brasília: MEC/PROINFO, 2006.

GALIAZZI, Maria., MORAES, Roque. Análise textual discursiva: processo reconstrutivo de múltiplas faces. Ciência e Educação, volume 9, 2007.

KENSKI, V. M. Das salas de aula aos ambientes virtuais de aprendizagem. In: 12॰ Congresso Internacional de Educação a Distância, 2005. Disponível em <http://www.abed.org.br/congresso2005>. Acesso em 08/04/2010.

LÉVY, Pierre. Cibercultura. São Paulo: Editora 34, 1999.

MORAN. José Manuel. Professores e gestores previsíveis e os inovadores. Disponível no site: http://www.eca.usp.br/prof/moran/previsiveis.htm. Acesso em 04/03/11. 
MASON, R. (1998). Using communications media in open and flexible learning. London: Kogan Page 